\title{
Effect of entecavir in the treatment of patients with hepatitis B virus-related compensated and decompensated cirrhosis
}

\author{
XIAO-DONG GAI and WEI-FENG WU \\ The Second Department of Liver Medicine, The Second Affiliated Hospital of \\ Southeast University, Nanjing, Jiangsu 210003, P.R. China \\ Received August 2, 2016; Accepted May 11, 2017
}

DOI: $10.3892 /$ etm.2017.4963

\begin{abstract}
Chronic hepatitis B virus (CHB) infection is a burden on global healthcare and is associated with a higher risk of serious sequelae, including cirrhosis and hepatocellular carcinoma. The clinical application of entecavir as a treatment for $\mathrm{CHB}$ has produced positive outcomes, and so is an attractive form of pharmacological therapy. However, little data exists comparing the safety and efficacy of entecavir for the treatment of hepatitis B virus (HBV)-related compensated, and decompensated cirrhosis, respectively. The aim of the present study was to evaluate entecavir therapy as a treatment for patients with HBV-related compensated and decompensated cirrhosis. A retrospective analysis of 46 compensated patients (compensated group) and 51 decompensated cirrhotic patients (decompensated group) treated with entecavir was conducted. Baseline demographics, clinical outcomes, and adverse events during the treatment were compared. Treatment with entecavir for 96 weeks resulted in significant improvements in serum levels of HBV DNA $(\mathrm{P}=0.002)$, albumin $(\mathrm{P}=0.014)$, cholinesterase (CHE; $\mathrm{P}=0.001)$, HBV DNA negativity rate $(\mathrm{P}=0.004)$, Child-Turcotte-Pugh score $(\mathrm{P}=0.030)$, alanine aminotransferase normalized rate $(\mathrm{P}=0.039)$, and the degree of esophageal varices liver stiffness $(\mathrm{P}=0.002)$ in the two groups. However, statistical analysis revealed that the improvements were significantly higher in the compensated group compared with the decompensated group $(\mathrm{P}<0.05)$. The complement component (C)3 and C4 levels were also significantly increased in the compensated group compared with the decompensated group at weeks 24,48 and $96(\mathrm{P}<0.05)$. In addition, the incidences of hepatocellular carcinoma, upper digestive tract hemorrhage and ascites were significantly higher in the decompensated group compared with the compensated group $(\mathrm{P}<0.05)$. In conclusion, treatment
\end{abstract}

Correspondence to: Dr Wei-Feng Wu, The Second Department of Liver Medicine, The Second Affiliated Hospital of Southeast University, 1-1 Zhongfu Road, Nanjing, Jiangsu 210003, P.R. China E-mail: weifengdogdndx@yeah.net

Key words: entecavir, efficacy, hepatitis B virus, complement, cirrhosis with 96-week entecavir therapy produced similar clinical outcomes in compensated and decompensated cirrhotic patients via inhibiting HBV-DNA viral load and recovering complement $\mathrm{C} 3$ and $\mathrm{C} 4$; however, entecavir exerts a better effect on patients with compensated cirrhosis, and so this therapy may improve the prognosis of such patients.

\section{Introduction}

Chronic hepatitis $\mathrm{B}(\mathrm{CHB})$ is an urgent global public health problem that affects $350-400$ million people worldwide (1). In China, $7 \%$ of individuals are diagnosed as carriers of hepatitis B virus (HBV) (2). An epidemiological survey reported that $15-40 \%$ of HBV carriers are at a higher risk of serious sequelae, including cirrhosis and hepatocellular carcinoma (HCC) (3). Cirrhosis is the end stage of chronic liver damage, which is reflected by liver fibrosis and liver architecture destruction (4). HBV, Hepatitis C (HCV) and alcohol consumption are major contributors to the development of cirrhosis, of which HBV infection accounts for $\sim 1 / 3$ of cirrhosis cases globally (5). Patients with cirrhosis have high morbidity associated with liver dysfunction and portal hypertension (6), and the 5-year survival rate of patients with decompensated cirrhosis is $14 \%$, whereas it is $84 \%$ in patients with compensated cirrhosis (7). Decompensated cirrhosis was established if there were ascites, variceal bleeding or hepatic encephalopathy, or if the Child-Turcotte-Pugh (CTP) score was class B or $\mathrm{C}$, whereas compensated cirrhosis was diagnosed as either HBeAg-positive or HBeAg-negative with an initial HBV DNA level $>2,000 \mathrm{IU} / \mathrm{ml}$ with evidence of chronic hepatitis $(8,9)$. It is therefore important to develop novel strategies for the prevention and treatment of HBV-related liver diseases in clinical practice.

Antiviral agents are recommended to treat $\mathrm{CHB}$ and HCC development (10). The current therapy drugs include adefovir, tenofovir disoproxil fumarate, lamivudine (LAM), telbivudine and entecavir (11); however, LAM has been identified as having high drug resistance, and is no longer used as a first-line therapy for patients with CHB (12). Multiple clinical studies have proposed that entecavir may be used as a primary agent for patients with HBV-related liver cirrhosis irrespective of $\mathrm{HBeAg}$ serostatus $(9,13,14)$. Entecavir is an antiviral agent that has been demonstrated to be an effective treatment of CHB (8). In a previous report, a 48-week period of 
entecavir therapy resulted in clear improvements in 57-59\% of patients with CHB and advanced liver fibrosis/cirrhosis (15). Entecavir has also been recognized as a valuable alternative for nucleos(t)ide-naive patients, having the advantages of lower drug resistance rates and stronger antiviral effects (16).

Although the clinical efficacy of entecavir in patients with hepatitis B virus-related cirrhosis has been demonstrated in many studies, data comparing the clinical outcomes with entecavir in patients with HBV-related compensated or decompensated cirrhosis are limited. The aim of the present prospective study was to compare the clinical outcomes of compensated cirrhosis patients and decompensated cirrhosis patients in China.

\section{Patients and methods}

Study population. The present study was approved by the Ethics Committee of The Second Affiliated Hospital of Southeast University (Nanjing, China), and was conducted following the ethical standards for human experimentation. All experiments were performed in accordance with the Declaration of Helsinki and other relevant guidelines and regulations. Signed informed consent was obtained from the subjects for participation in the study. A total of 91 patients diagnosed with HBV-related cirrhosis between January 2009 and March 2014 at The Second Department of Liver Medicine, The Second Affiliated Hospital of Southeast University were enrolled in the present study. Cirrhosis was diagnosed based on histological assessments of the liver, clinical symptoms, endoscopic examination, laboratory analysis, and sonographic results. Diagnoses of compensated and decompensated cirrhosis were made following liver disease management guidelines, including Child-Turcotte-Pugh score (14). Child-Turcotte-Pugh scores of 5 or 6, 7-9, or 10-15 were treated as Child-Pugh class A, B, or $\mathrm{C}$, respectively. The inclusion criteria of the present study were as follows: i) Adults aged $>16$ years with $\mathrm{CHB}$ infection; ii) $\mathrm{HBV}$ surface antigen ( $\mathrm{HBs} \mathrm{Ag}$ ) positivity for $>6$ months with detectable HBV surface antigen and/or serum HBV DNA; iii) adequate pre- and post-treatment biopsy samples; and iv) a diagnosis of compensated or decompensated cirrhosis (17). The exclusion criteria of the present study included the following: i) Co-infection with hepatitis A virus, HCV or hepatitis D virus; ii) patients who had received antiviral therapy involving interferon-a or nucleos(t)ide analogs; iii) patients who suffered from HCC or other malignancies; and iv) patients who had a history of liver or other organ transplantation (18). According to the inclusion criteria and exclusion criteria, 46 patients with compensated cirrhosis and 51 patients with decompensated cirrhosis were enrolled in the present study. The compensated and decompensated cirrhotic patients were treated with conventional liver protecting and enzyme-reducing pharmacological agents, including glutathione (Shanghai Fudan Fuhua Pharmaceutical Co., Ltd., Shanghai, China; intravenous injection; $1.8 \mathrm{~g} / 250 \mathrm{ml}$ glucose solution), tiopronin (Henan Province Xinyi Pharmaceutical Ltd., Xinxiang, China; intravenous injection; $0.1 \mathrm{~g} / 250 \mathrm{ml}$ glucose solution), diammonium glycyrrhizinate (Chia Tai Tianqing Pharmaceutical Group Co., Ltd., Nanjing, China; intravenous injection; $150 \mathrm{mg} / 250 \mathrm{ml}$ glucose solution) and underwent oral administration of $0.5 \mathrm{mg} /$ day entecavir treatment (Chia Tai Tianqing Pharmaceutical Group Co., Ltd., Nanjing, China) for 96 weeks.
Laboratory and radiological testing. Liver biopsy samples were collected from each patient prior to treatment (baseline) and then at weeks 24, 48 and 96. The specimens were fixed in $4 \%$ formaldehyde (Nanjing Institute of Biological Engineering; Nanjing, China) for $24 \mathrm{~h}$ at room temperature, embedded in paraffin, cut into $5-\mu \mathrm{m}$ thick sections and stained with hematoxylin for $1 \mathrm{~min}$ and eosin for $3 \mathrm{~min}$ at room temperature (Nanjing Institute of Biological Engineering). Images were obtained with an Olympus BX51 microscope (Olympus Corp., Tokyo, Japan) and were assessed by different independent histopathologists. Serum hepatitis B viral markers including hepatitis B e antigen ( $\mathrm{HBeAg}$ ), antibody to $\mathrm{HBeAg}$ and antibody to $\mathrm{HBsAg}$ were measured using an ELISA kit (ABBOTT PRISM; 34-3979R10; Abbott Pharmaceutical Co., Ltd., Lake Bluff, IL, USA). Serum HBV DNA levels were detected using a commercial polymerase chain reaction kit (1496123765; Da An Gene Co., Ltd., Sun Yat-sen University, Guangzhou, China). Patients were deemed to be HBV negative with a detection limit of 500 copies $/ \mathrm{ml}$. The HBV DNA negativity was defined as the serum HBV DNA was <500 copies/ml (9). Endoscopic examinations were performed to assess esophagogastric varices and liver stiffness was assayed using a FibroScan System (Fibroscan-502; Echosens, Paris, France) according to the manufacture's protocol. The enrolled patient was in either a supine or a left decubitus position with maximal abduction of the left arm; the probe was positioned in an intercostal space where the spleen was correctly visualized as described previously $(19,20)$. Alanine aminotransferase (ALT) in the serum was detected using a Wuhan Paiya HCC-8622 Automatic Biochemical Instrument (Wuhan Xin Desheng medical instruments Co., Ltd., Wuhan, China). The serum ALT levels in the enrolled patients were decreased to 5-40 U/1 after treatment, which was taken as the normalized ALT (9,21). A conventional autoanalyzer (Assembly Line ADV1A2400, Bayer Corporation, Leverkusen, Germany) was used to determine the serum albumin (ALB) levels in accordance with the manufacture's protocols. The levels of cholinesterase (CHE) were measured using a photochemical method with the VITROSAS51 instrument (Johnson \& Johnson, New Brunswick Brown, NJ, USA) in accordance with the manufacturer's specification as described previously (21). Serum complement component (C)3 and C4 levels were tested using immunonephelometry (Wako Pure Chemical Industries, Ltd., Osaka, Japan). Other laboratory parameters, including complete blood count were analyzed with standard analytical procedures using an automatic biochemical analyzer (8020A; Gates Unitta; Guilin, China).

Statistical analysis. Quantitative data are expressed as the mean \pm standard deviation or as a percentage, and proportions are presented as a percentage. Each experiment was repeated 3 times. SPSS version 19.0 software (IBM Corp., Armonk, NY, USA) was used for data analysis. Fisher's exact test was used to compare frequencies and Student's t-tests or Mann Whitney $U$ tests were used to compare continuous variables between groups. Multiple comparisons at different time points were made using one or two-way analysis of variance and $\chi^{2}$ tests was used to compare the categorical data. $\mathrm{P}<0.05$ was considered to indicate a statistically significant difference. 
Table I. Baseline characteristics of patients in two groups.

\begin{tabular}{|c|c|c|c|}
\hline \multirow[b]{2}{*}{ Characteristics } & \multicolumn{2}{|c|}{ Group } & \multirow[b]{2}{*}{ P-value } \\
\hline & Compensated & Decompensated & \\
\hline $\mathrm{N}$ & 46 & 51 & \\
\hline Age, years & $51.2 \pm 13.1$ & $53.4 \pm 13.1$ & 0.442 \\
\hline \multicolumn{4}{|l|}{ Sex, n (\%) } \\
\hline Male & $31(67.4)$ & $33(64.7)$ & 0.780 \\
\hline Female & $15(32.6)$ & $18(35.3)$ & \\
\hline \multicolumn{4}{|l|}{ Ethnicity, n (\%) } \\
\hline Han & $44(95.7)$ & $50(98.0)$ & 0.498 \\
\hline Minority & $2(4.3)$ & $1(2.0)$ & \\
\hline Body mass index, $\mathrm{kg} / \mathrm{m}^{2}$ & $23.1 \pm 1.8$ & $22.9 \pm 1.9$ & 0.566 \\
\hline Hepatitis B e antigen positivity, $\mathrm{n}(\%)$ & $25(61.0)$ & $30(58.8)$ & 0.657 \\
\hline $\begin{array}{l}\text { Hepatitis B virus DNA, } \\
\log _{10} \text { copies } / \mathrm{ml}\end{array}$ & $5.9 \pm 1.4$ & $5.8 \pm 1.9$ & 0.771 \\
\hline Alanine aminotransferase, $\mathrm{U} / \mathrm{l}$ & $125.6 \pm 71.6$ & $103.6 \pm 85.2$ & 0.618 \\
\hline \multicolumn{4}{|l|}{ Esophageal varices, n (\%) } \\
\hline None & $8(17.4)$ & $0(0)$ & 0.006 \\
\hline Mild & $20(43.5)$ & $15(29.4)$ & 0.150 \\
\hline Moderate & $9(19.6)$ & $16(31.4)$ & 0.184 \\
\hline Severe & $9(19.6)$ & $20(39.2)$ & 0.035 \\
\hline Child-Turcotte-Pugh score & $5.8 \pm 1.1$ & $8.1 \pm 1.6$ & $<0.001$ \\
\hline Albumin, $\mathrm{g} / \mathrm{l}$ & $35.8 \pm 7.1$ & $29.8 \pm 4.7$ & $<0.001$ \\
\hline Cholinesterase, IU/l & $4,065.3 \pm 1,679.2$ & $2,890.1 \pm 1,037.1$ & $<0.001$ \\
\hline Liver stiffness, $\mathrm{kPa}$ & $18.2 \pm 4.1$ & $30.5 \pm 8.9$ & $<0.001$ \\
\hline
\end{tabular}

Data are presented as the mean \pm standard deviation, unless otherwise stated.

\section{Results}

Patient demographics. The baseline characteristics of the compensated and decompensated cirrhotic groups are presented in Table I. A total of 97 patients with hepatitis B virus-related cirrhosis, including 64 males and 33 females, were divided into 46 compensated and 51 decompensated cases. No significant differences were observed between the two groups in age, sex ratio, ethnicity, body mass index, $\mathrm{HBeAg}$ positivity or HBV DNA concentration. Child-Turcotte-Pugh scores, liver stiffness and incidence of severe esophageal varices were significantly lower in the compensated group compared with the decompensated group $(\mathrm{P}<0.05)$, whereas the serum ALB and $\mathrm{CHE}$ levels, and the incidence of no esophageal varices were significantly higher in the compensated group compared with the decompensated group $(\mathrm{P}<0.05)$.

Changes in ALB, CHE and HBV DNA prior to and following treatment. Entecavir therapy for 96 weeks resulted in a significant decrease in serum HBV DNA and significant increases in ALB and CHE in both groups $(\mathrm{P}<0.05$; Table II). In the compensated group, the level of HBV DNA decreased and levels of ALB and CHE increased in a time-dependent manner at weeks 24, 48 and 96 compared with the baseline at 0 week
$(\mathrm{P}<0.05$; Table II). No significant statistical differences were observed in the levels of HBV DNA, ALB and CHE in the decompensated group following 24 or 48 weeks of treatment compared with the baseline at 0 weeks; however, the HBV DNA, ALB and CHE levels were significantly ameliorated at week 96 compared with the baseline $(\mathrm{P}<0.05$; Table II). Statistical differences were observed between the compensated group and decompensated group in terms of HBV DNA, ALB and CHE from week 24 to week 96 (P<0.05; Table II).

HBV DNA negativity rate following treatment with entecavir. The HBV DNA negativity rate was significantly higher in the compensated group compared with the decompensated group at weeks 24, 48, and $96(\mathrm{P}<0.05$; Table III).

Changes in Child-Turcotte-Pugh score prior to and following treatment. Significant differences were observed in Child-Turcotte-Pugh scores between the two groups prior to treatment $(\mathrm{P}<0.05$; Table IV). The Child-Turcotte-Pugh score in the compensated group was significantly lower at weeks 24, 48 and 96 compared with the baseline ( $\mathrm{P}<0.05$; Table IV). The Child-Turcotte-Pugh score in the decompensated was significantly higher at all time points compared with the compensated group $(\mathrm{P}<0.05$; Table IV), and was significantly 
Table II. Change in albumin, cholinesterase and hepatitis B virus DNA prior to and following treatment with entecavir.

\begin{tabular}{|c|c|c|}
\hline \multirow[b]{2}{*}{ Characteristics } & \multicolumn{2}{|c|}{ Group } \\
\hline & Compensated & Decompensated \\
\hline \multicolumn{3}{|l|}{ Albumin, g/l } \\
\hline Week 0 & $35.8 \pm 7.1$ & $29.8 \pm 4.7$ \\
\hline Week 24 & $39.2 \pm 6.3^{\mathrm{a}, \mathrm{b}}$ & $30.1 \pm 4.9$ \\
\hline Week 48 & $41.3 \pm 5.5^{\mathrm{a}, \mathrm{b}}$ & $31.2 \pm 5.4$ \\
\hline Week 96 & $43.2 \pm 5.1^{\mathrm{a}, \mathrm{b}}$ & $36.9 \pm 6.1^{\mathrm{c}}$ \\
\hline \multicolumn{3}{|c|}{ Cholinesterase, IU/1 } \\
\hline Week 0 & $4,065.3 \pm 1,679.2$ & $2,890.1 \pm 1,037.1$ \\
\hline Week 24 & $4,782.3 \pm 1,716.2^{\mathrm{a}, \mathrm{b}}$ & $2,948.2 \pm 1,123.4$ \\
\hline Week 48 & $5,893.2 \pm 1,842.2^{\mathrm{a}, \mathrm{b}}$ & $3,158.3 \pm 1,247.2$ \\
\hline Week 96 & $6,541.1 \pm 1,913.4^{\mathrm{a}, \mathrm{b}}$ & $3,873.3 \pm 1,216.8^{\mathrm{c}}$ \\
\hline \multicolumn{3}{|c|}{$\begin{array}{l}\text { Hepatitis B virus DNA, } \\
\log _{10} \text { copies } / \mathrm{ml}\end{array}$} \\
\hline Week 0 & $5.9 \pm 1.4$ & $5.8 \pm 1.9$ \\
\hline Week 24 & $4.3 \pm 1.6^{\mathrm{a}, \mathrm{b}}$ & $5.6 \pm 1.5$ \\
\hline Week 48 & $3.4 \pm 1.2^{\mathrm{a}, \mathrm{b}}$ & $4.7 \pm 1.2$ \\
\hline Week 96 & $2.3 \pm 0.9^{\mathrm{a}, \mathrm{b}}$ & $4.2 \pm 1.1^{\mathrm{c}}$ \\
\hline
\end{tabular}

Table III. Hepatitis B virus DNA negativity rate following treatment with entecavir.

\begin{tabular}{lccc}
\hline \multirow{2}{*}{$\begin{array}{l}\text { Hepatitis B } \\
\text { virus DNA } \\
\text { negativity rate }\end{array}$} & Compensated & Decompensated & P-value \\
\cline { 2 - 3 } & $27(58.7)$ & $15(29.4)$ & 0.004 \\
Week 24 & $36(78.2)$ & $24(47.1)$ & 0.002 \\
Week 48 & $40(87.0)$ & $31(60.7)$ & 0.004 \\
Week 96 & & & \\
\hline
\end{tabular}

decreased at weeks 48 and 96 compared with the baseline $(\mathrm{P}<0.05$; Table IV). At week 96, the Child-Turcotte-Pugh scores were improved or stable for all patients in the compensated group; 24 patients were improved and 22 cases were stable. However, in the decompensated group, 19 patients were improved, 21 showed steady condition, and 11 had deteriorated (Table IV). The number of patients who exhibited signs of deterioration was significantly higher in the decompensated group compared with the compensated group $(\mathrm{P}<0.05$; Table IV).

Change in the ALT normalized rate following treatment with entecavir. The serum ALT levels in the enrolled patients were decreased to 5-40 U/1 after treatment, which was regarded as the normalized ALT. As presented in Table V, the ALT normalized rate gradually increased in both groups in a time-dependent manner; however, the rate was significantly higher in the
Table IV. Change in Child-Turcotte-Pugh score prior to and following treatment with entecavir.

\begin{tabular}{lcc}
\hline \multicolumn{2}{c}{ Group } \\
\cline { 2 - 3 } Characteristics & Compensated & Decompensated \\
\hline Child-Turcotte- & \\
Pugh score & \\
Week 0 & $5.8 \pm 1.1^{\mathrm{a}}$ & $8.1 \pm 1.6$ \\
Week 24 & $5.2 \pm 1.2^{\mathrm{a}, \mathrm{b}}$ & $7.9 \pm 1.7$ \\
Week 48 & $4.1 \pm 1.1^{\mathrm{a}, \mathrm{b}}$ & $6.6 \pm 1.2^{\mathrm{c}}$ \\
Week 96 & $1.6 \pm 0.7^{\mathrm{a}, \mathrm{b}}$ & $5.2 \pm 1.1^{\mathrm{c}}$ \\
Child-Turcotte- & & \\
Pugh score, $\mathrm{n}(\%)$ & & $19(37.2)$ \\
Improvement & $24(52.2)$ & $21(41.2)$ \\
Stabilization & $22(47.8)$ & $11(21.6)$ \\
Deterioration & $0(0)^{\mathrm{b}}$ & \\
\hline
\end{tabular}

Data are presented as the mean \pm standard deviation, unless otherwise stated. ${ }^{\mathrm{a}} \mathrm{P}<0.05$ vs. Week 0 in the Compensated group, ${ }^{\mathrm{b}} \mathrm{P}<0.05$ vs. Decompensated group at the same time, ${ }^{\mathrm{c}} \mathrm{P}<0.05 \mathrm{vs}$. Week 0 in the Decompensated group.

Table V. Change in the alanine aminotransferase normalized rate prior to and following treatment with entecavir.

\begin{tabular}{lccc}
\hline $\begin{array}{l}\text { Alanine } \\
\text { aminotransferase } \\
\text { normalized rate }\end{array}$ & Compensated & Decompensated & \\
\cline { 2 - 3 } & P-value \\
\hline Week 24 & $31(67.3)$ & $17(33.3)$ & 0.001 \\
Week 48 & $35(76.1)$ & $26(51.0)$ & 0.011 \\
Week 96 & $42(91.3)$ & $38(74.5)$ & 0.030 \\
\hline
\end{tabular}

compensated group compared with the decompensated group at all time points $(\mathrm{P}<0.05)$.

Change in the degree of esophageal varices following treatment. The severe esophageal varices were significantly lower in the compensated group compared with the decompensated group prior to treatment $(\mathrm{P}=0.035$; Table VI) and the number of patients with no esophageal varices in the compensated group was significantly higher compared with that in the decompensated group before treatment $(\mathrm{P}=0.006$; Table VI). However, the improvement in degree of esophageal varices after the treatment was superior in the compensated group, with the exception of mild esophageal varices $(\mathrm{P}<0.01$ for none, $\mathrm{P}=0.005$ for Moderate and $\mathrm{P}=0.039$ for severe; Table VI). The degree of esophageal varices decreased in 8 patients in the compensated group and in 3 patients from the decompensated group (Table VI).

Change in the liver stiffness value in two groups. Liver stiffness was significantly lower in patients with compensated cirrhosis compared with patients in the decompensated group 
Table VI. Change in the degree of esophageal varices prior to and following treatment with entecavir.

\begin{tabular}{lrcr}
\hline & \multicolumn{2}{c}{ Group, n (\%) } & \\
\cline { 2 - 3 } $\begin{array}{l}\text { Esophageal } \\
\text { varices }\end{array}$ & Compensated & Decompensated & P-value \\
\hline Week 0 & & & \\
None & $8(17.4)$ & $0(0)$ & 0.006 \\
Mild & $20(43.5)$ & $15(29.4)$ & 0.150 \\
Moderate & $9(19.6)$ & $16(31.4)$ & 0.184 \\
Severe & $9(19.6)$ & $20(39.2)$ & 0.035 \\
Week 96 & & & \\
None & $12(26.1)$ & $0(0)$ & $<0.001$ \\
Mild & $22(47.8)$ & $16(31.4)$ & 0.097 \\
Moderate & $5(10.9)$ & $18(35.3)$ & 0.005 \\
Severe & $7(15.2)$ & $17(33.3)$ & 0.039 \\
\hline
\end{tabular}



Figure 1. Changes in liver stiffness in patients with compensated and decompensated cirrhosis prior to and following entecavir treatment. ${ }^{*} \mathrm{P}<0.05$ vs. Week $0 ;{ }^{\dagger} \mathrm{P}<0.05$ vs. decompensated group.

prior to treatment $(\mathrm{P}<0.05$; Fig. 1). Liver stiffness decreased in a time-dependent manner in both groups, however, no statistically significant difference in liver stiffness was observed in the decompensated group at weeks 24 or 48 compared with the baseline. Liver stiffness was observed to be significantly lower in the compensated group compared with the decompensated group at weeks 24,48 and $96(\mathrm{P}<0.05$; Fig. 1$)$.

Changes in serum complement $C 3$ and $C 4$. Levels of serum complement $\mathrm{C} 3$ and $\mathrm{C} 4$ were significantly higher in the compensated group compared with the decompensated group at the baseline and at weeks 24, 48 and $96(\mathrm{P}<0.05$; Fig. 2). Serum complement $\mathrm{C} 3$ and $\mathrm{C} 4$ levels were significantly higher in the compensated group at weeks 48 and 96 compare with week 0 ( $\mathrm{P}<0.05$; Fig. 2) However, there was no statistically significant difference in complement $\mathrm{C} 3$ and $\mathrm{C} 4$ levels in the decompensated group at weeks 24,48 and 96 compared with the baseline at week 0 .
Clinical events during the treatment process. During the treatment period, no serious clinical adverse events were recorded in either group. However, the incidence of HCC, hemorrhage of the upper digestive tract and ascites were significantly higher in the decompensated group compared with the compensated cirrhotic patients $(\mathrm{P}<0.05$; Table VII).

\section{Discussion}

HBV is most commonly presented in patients with chronic liver infection, among whom $10-20 \%$ have progressed to cirrhosis (22). The continuous inhibition of HBV replication has been proposed as a principal therapy for HBV-related cirrhosis (23). A recent study indicated that antiviral therapy may improve the clinical outcome and reduce the incidence of $\mathrm{HCC}$ in patients with HBV-related cirrhosis (11). Entecavir has recently been recommended as a potential antiviral agent and been extensively used for treatment of CHB (24). The results of the present study demonstrate that entecavir therapy for 96 weeks improves serum levels of HBV DNA, ALB, and CHE, and improves the HBV DNA negativity rate, Child-Turcotte-Pugh score, ALT normalized rate, degree of esophageal varices and liver stiffness. These improvements were significantly increased in the compensated group compared with the decompensated group. Furthermore, complement $\mathrm{C} 3$ and $\mathrm{C} 4$ levels were significantly increased in the compensated group compared with the decompensated group at weeks 24, 48 and 96. The incidences of HCC, upper digestive tract hemorrhage and ascites were significantly higher in the decompensated group compared with the compensated group. These results suggest that entecavir is an effective and safe treatment for patients with HBV-related compensated and decompensated cirrhosis, and that entecavir exerts a better effect on patients with compensated cirrhosis.

Treatment of HBV-related cirrhosis requires prolonged antiviral therapy for sustained depression of HBV replication $(21,25)$. The seroclearance of HBeAg and HBV DNA are critical indicators of progression in chronic HBV infection (26). A previous clinical study reported that 6 years of cumulative entecavir therapy resulted in improvements in liver histology and Ishak fibrosis scores (27). A prospective study also demonstrated that entecavir therapy resulted in an HBV DNA level of $<500$ copies $/ \mathrm{ml}$ in $88 \%$ of compensated and $93 \%$ of decompensated cirrhosis cases (25). In the present study, it was demonstrated that the HBV DNA negativity rate was higher in the compensated group compared with the decompensated group at weeks 24, 48, and 96. Entecavir therapy for 96 weeks resulted in decreased serum HBV DNA levels in both groups. In the compensated group, the levels of HBV DNA were progressively improved at weeks 24,48 and 96 in comparison with the baseline at week 0 , and significant differences in HBV DNA levels were observed between the compensated and decompensated groups from week 24-96. In addition, the ALT normalized rate increased gradually in both groups, and the rate was significantly higher in the compensated compared with the decompensated group. These results suggest that application of entecavir is more effective in the patients with compensated cirrhosis than those with decompensated cirrhosis.

Serum levels of ALB and CHE are major indicators of liver function $(25,28)$. It has been reported that patients with 
Table VII. Clinical events during the treatment process.

\begin{tabular}{lccc}
\hline & \multicolumn{2}{c}{ Group, n (\%) } & \\
\cline { 2 - 3 } Clinical events & Compensated & Decompensated & P-value \\
\hline $\begin{array}{l}\text { Hepatocellular } \\
\text { carcinoma }\end{array}$ & $1(2.2)$ & $7(13.7)$ & 0.039 \\
$\begin{array}{l}\text { Hemorrhage of } \\
\text { upper digestive }\end{array}$ & $2(4.3)$ & $14(27.5)$ & 0.002 \\
$\begin{array}{l}\text { tract } \\
\text { Ascites }\end{array}$ & $0(0)$ & $8(15.7)$ & 0.005 \\
\hline
\end{tabular}
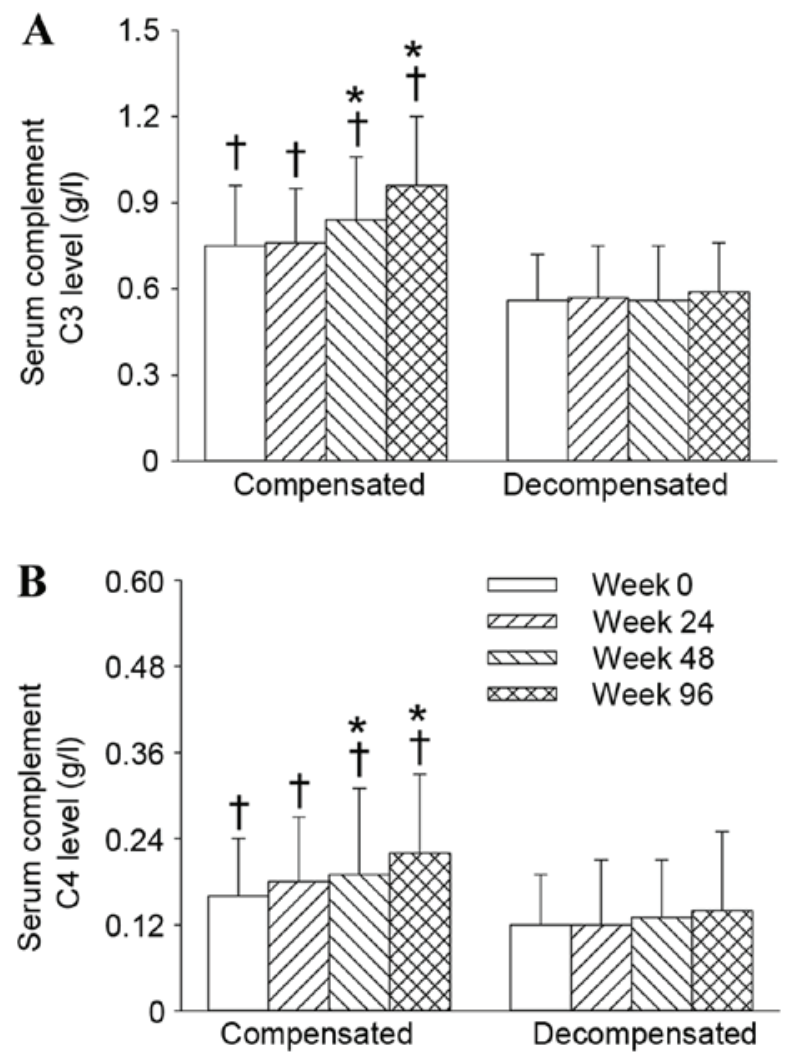

Figure 2. Changes in serum complement (A) C3 and (B) C4 levels in patients with compensated and decompensated cirrhosis prior to and following entecavir treatment. ${ }^{*} \mathrm{P}<0.05$ vs. Week $0 ;{ }^{\dagger} \mathrm{P}<0.05$ vs. decompensated group.

cirrhosis had lower ALB and CHE levels compared with healthy controls (13), and another study reported that entecavir treatment was able to increase ALB levels in patients with chronic hepatitis B or cirrhosis (29). Consistent with previous findings, entecavir therapy for 96 weeks resulted in increased ALB and CHE levels in both groups in the present study. In the compensated group, the levels of ALB and CHE were progressively improved over time compared with the baseline at week 0 . No significant statistical difference was observed in ALB and CHE levels in the decompensated group at weeks 24 and 48 compared with the baseline; however, these levels were significantly ameliorated at week 96. Significant differences were observed in ALB and CHE levels between the compensated and decompensated groups weeks 24-96. These results indicate that the liver synthetic function was improved more effectively in patients with compensated cirrhosis compared with patients with decompensated cirrhosis.

The Child-Turcotte-Pugh score is recognized as an effective system for evaluating liver function and the clinical prognosis of cirrhosis patients (30). A previous study reported that Child-Turcotte-Pugh scores were improved at the 1-year follow-up in response to entecavir and tenofovir therapy (31). In the present study, the Child-Turcotte-Pugh score in the compensated group decreased significantly with entecavir treatment in a time-dependent manner, and were significantly reduced at weeks 48 or 96 in the decompensated group in comparison with the baseline. The Child-Turcotte-Pugh scores were improved or stable for all patients in the compensated group at the end of the 96-week treatment period; 24 patients were improved and 22 cases were stable. However, in the decompensated group, 11 patients were demonstrated to have deteriorated at the end of the treatment period. These results suggest that long-term treatment with entecavir may improve liver function, slow the progression of cirrhosis and reduce the incidence of cirrhosis-related complications.

Portal hypertension may lead to esophagogastric varices in patients with cirrhosis, which is one of the most common cirrhosis-related complications (13). Liver stiffness is a critical marker used to evaluate the degree of liver fibrosis (21). Liver stiffness is positively associated with fibrosis stage, and the liver stiffness is significantly increased in patients with chronic HBV or HCV infection (32). In the present study, the severity of esophageal varices was lower in the compensated group compared with the decompensated group prior to treatment; however, a greater improvement was observed in the decompensated group. In addition, liver stiffness was significantly lower in patients with compensated cirrhosis compared with decompensated cirrhosis before treatment. Liver stiffness decreased with entecavir in a time-dependent manner in both groups. These results suggest that portal hypertension or liver fibrosis may be reversed by long-term administration of entecavir in patients with compensated or decompensated cirrhosis, which may be due to sustained HBV suppression by entecavir.

The occurrence of HBV-related cirrhosis may be associated with immune activation (33). The complement system is an important part of the immune system in humans, and serum levels of complement $\mathrm{C} 3$ and $\mathrm{C} 4$ serve an important role in human immunity (34). Serum complement C3 and C4 levels have previously been reported to be reduced in patients with HBV (35). In the present study, the serum levels of complement C3 and C4 were significantly higher in the compensated group compared with the decompensated group at the baseline. Complement C3 and C4 levels were significantly increased in the compensated group with entecavir treatment in a time-dependent manner. However, there was no significant improvement in complement C3 and C4 levels in the decompensated group throughout the treatment period. These results indicate immune function was better restored in patients with compensated cirrhosis compared with decompensated cirrhosis in response to entecavir therapy.

In conclusion, the results of the present study demonstrate that entecavir may be an effective treatment for HBV-related cirrhosis via reducing HBV DNA viral load, increasing liver 
function and activating the complement system. Based on the results of the present study, entecavir appears to be a more effective treatment for patients with compensated cirrhosis compared with patients with decompensated cirrhosis. Further investigation is required to assess the long-term efficacy of entecavir on cirrhosis patients.

\section{References}

1. Lefton HB, Rosa A and Cohen M: Diagnosis and epidemiology of cirrhosis. Med Clin North Am 93: 787-799, vii, 2009.

2. Bischoff A: Etiology of increased liver values from alcohol to hemochromatosis. Many roads lead to cirrhosis. MMW Fortschr Med 153: 22-23, 2011 (In German).

3. Li Q, Song J, Huang Y, Li X, Zhuo Q, Li W, Chen C, Lu C, Qi X and Chen L: The Gamma-Glutamyl-Transpeptidase to platelet ratio does not show advantages than APRI and Fib-4 in diagnosing significant fibrosis and cirrhosis in patients with Chronic Hepatitis B: A retrospective cohort study in china. Medicine (Baltimore) 95: e3372, 2016.

4. Guarino M, Tosoni A and Nebuloni M: Direct contribution of epithelium to organ fibrosis: Epithelial-mesenchymal transition. Human Pathol 40: 1365-1376, 2009.

5. Jia W, Qi X, Ji YY, Xun YH, Wang H, Zhang WH, Yang JH, Wang JY, Zhu HX, Mao RC and Zhang JM: Low serum Hepatitis B surface antigen level predicts compensated cirrhosis caused by chronic Hepatitis B in HBeAg positive patients in east china. Hepat Mon 15: e29183, 2015.

6. Ding R and Ma SW: Research advances in the role of interleukin-21 in chronic hepatitis B virus infection. Zhonghua Gan Zang Bing Za Zhi 24: 469-473, 2016 (In Chinese).

7. Yip VS, Poon RT, Chok KS, Chan AC, Dai WC, Tsang SH, Chan SC, Lo CM and Cheung TT: Comparison of survival outcomes between right posterior sectionectomy and right hepatectomy for hepatocellular carcinoma in cirrhotic liver: A single-centre experience. World J Surg 39: 2764-2770, 2015.

8. Yue-Meng W, Li YH, Wu HM, Yang J, Xu Y, Yang LH and Yang JH: Telbivudine versus lamivudine and entecavir for treatment-naïve decompensated hepatitis B virus-related cirrhosis. Clin Exp Med 17: 233-241, 2017.

9. Sriprayoon T, Mahidol C, Ungtrakul T, Chun-On P, Soonklang K, Pongpun W, Laohapand C, Dechma J, Pothijaroen C, Auewarakul $\mathrm{C}$ and Tanwandee T: Efficacy and safety of entecavir versus tenofovir treatment in chronic hepatitis B patients: A randomized controlled trial. Hepatol Res 47: E161-E168, 2017.

10. Adinolfi LE, Rinaldi L, Guerrera B, Restivo L, Marrone A, Giordano $M$ and Zampino R: NAFLD and NASH in HCV Infection: Prevalence and significance in hepatic and extrahepatic manifestations. Int J Mol Sci 17: pii: E803, 2016.

11. Ke W, Zhang C, Liu L, Gao Y, Yao Z, Ye X, Zhou S and Yang Y: Cost-effectiveness analysis of tenofovir disoproxil fumarate for treatment of chronic hepatitis B in China. Hepatol Int 10: 924-936, 2016.

12. Lingala S, Lau DT, Koh C, Auh S, Ghany MG and Hoofnagle JH: Long-term lamivudine therapy in chronic hepatitis B. Aliment Pharmacol Ther 44: 380-389, 2016.

13. Kim IS, Mun JI,KooJH, Kang CJ,BakJK, Cheong JY and ChoSW: Entecavir therapy for patients with hepatitis B virus-related decompensated cirrhosis. Korean J Gastroenterol 59: 224-231, 2012.

14. Shen H, Ding F, Wang Z, Sun F, Yu Y, Zhou J, Xu W, Ni J, Wang J and Yang Y: comparison of telbivudine and entecavir therapy on nephritic function and drug resistance in patients with hepatitis B virus-related compensated cirrhosis. Cell Physiol Biochem 40: 370-378, 2016

15. Wang JL, Du XF, Chen SL, Yu YQ, Wang J, Hu XQ, Shao LY, Chen JZ, Weng XH and Zhang WH: Histological outcome for chronic hepatitis B patients treated with entecavir vs lamivudine-based therapy. World J Gastroenterol 21: 9598-9606, 2015.

16. Zhang D, Jiao Z, Han J and Cao H: Clinicopathological features of hepatitis $\mathrm{B}$ virus recurrence after liver transplantation: Eleven-year experience. Int J Clin Exp Pathol 7: 4057-4066, 2014

17. Kong D, Chen X, Lu S, Guo Q, Lai W, Wu J, Lin D, Zeng D, Duan B, Jiang T and Cao J: Short-term effects of splenectomy on serum fibrosis indexes in liver cirrhosis patients. Int J Clin Exp Pathol 8: 15260-15264, 2015
18. Yao L, Xing S, Fu X, Song H, Wang Z, Tang J and Zhao Y: Association between interleukin-10 gene promoter polymorphisms and susceptibility to liver cirrhosis. Int J Clin Exp Pathol 8: 11680-11684, 2015.

19. Wong GL, Kwok R, Chan HL, Tang SP, Lee E, Lam TC, Lau TW, Ma TM, Wong BC and Wong VW: Measuring spleen stiffness to predict varices in chronic hepatitis B cirrhotic patients with or without receiving non-selective beta-blockers. J Dig Dis 17: 538-546, 2016.

20. Shen J, Wong GL, Chan HL, Chan HY, Yeung DK, Chan RS, Chim AM, Chan AW, Choi PC, Woo J, et al: PNPLA3 gene polymorphism accounts for fatty liver in community subjects without metabolic syndrome. Aliment Pharmacol Ther 39: 532-539, 2014

21. Yang X, Li J, Zhou L, Liu J, Wang J and Lu W: Comparison of telbivudine efficacy in treatment-naive patients with hepatitis $\mathrm{B}$ virus-related compensated and decompensated cirrhosis in 96 weeks. Eur J Gastroenterol Hepatol 26: 396-403, 2014.

22. Meng Y, Xu BQ, Fu ZG, Wu B, Xu B, Chen ZN and Li L: Cytoplasmic EpCAM over-expression is associated with favorable clinical outcomes in pancreatic cancer patients with Hepatitis B virus negative infection. Int J Clin Exp Med 8: 22204-22216, 2015.

23. Qi Z, Wang H and Gao G: Association of risk of non-Hodgkin's lymphoma with hepatitis B virus infection: A meta-analysis. Int J Clin Exp Med 8: 22167-22174, 2015.

24. Li X, Jie Y, You X, Shi H, Zhang M, Wu Y, Lin G, Li X, Gao Z and Chong Y: Optimized combination therapies with adefovir dipivoxil (ADV) and lamivudine, telbivudine, or entecavir may be effective for chronic hepatitis B patients with a suboptimal response to ADV monotherapy. Int J Clin Exp Med 8: 21062-21070, 2015.

25. Xu Y, Zhang YG, Wang X, Qi WQ, Qin SY, Liu ZH, Jiao J and Wang JB: Long-term antiviral efficacy of entecavir and liver histology improvement in Chinese patients with hepatitis B virus-related cirrhosis. World J Gastroenterol 21: 7869-7876, 2015.

26. Yang HI, Hung HL, Lee MH, Liu J, Jen CL, Su J, Wang LY, Lu SN, You SL, Iloeje UH, et al: Incidence and determinants of spontaneous seroclearance of hepatitis B e antigen and DNA in patients with chronic hepatitis B. Clin Gastroenterol Hepatol 10: 527-534, 2012.

27. Schiff ER, Lee SS, Chao YC, Kew Yoon S, Bessone F, Wu SS, Kryczka W, Lurie Y, Gadano A, Kitis G, et al: Long-term treatment with entecavir induces reversal of advanced fibrosis or cirrhosis in patients with chronic hepatitis B. Clin Gastroenterol Hepatol 9: 274-276, 2011.

28. Lv GC, Yao JM, Yang YD, Zheng L, Sheng JF, Chen Y and Li LJ: Efficacy of combined therapy in patients with hepatitis B virus-related decompensated cirrhosis. World J Gastroenterology 19: 3481-3486, 2013.

29. Saito M, Seo Y, Yano Y, Momose K, Hirano H, Yoshida M and Azuma T: Serum albumin and prothrombin time before entecavir treatment in chronic hepatitis B or cirrhosis are related to amelioration of liver function after treatment. Eur J Gastroenterol Hepatol 25: 1369-1376, 2013.

30. Liaw YF, Sung JJ, Chow WC, Farrell G, Lee CZ, Yuen H, Tanwandee T, Tao QM, Shue K, Keene ON, et al: Lamivudine for patients with chronic hepatitis B and advanced liver disease. N Engl J Med 351: 1521-1531, 2004.

31. Liaw YF, Sheen IS, Lee CM, Akarca US, Papatheodoridis GV, Suet-Hing Wong F, Chang TT, Horban A, Wang C, Kwan P, et al: Tenofovir disoproxil fumarate (TDF), emtricitabine/TDF and entecavir in patients with decompensated chronic hepatitis B liver disease. Hepatology 53: 62-72, 2011.

32. Han Z, Shi Y, Zhu J, Chen Y, Yin F, Xia L, Luo G, Gao Z, Liu J, Jia G, et al: Forty-eight-week retrospective study of telbivudine and lamivudine treatment in patients with hepatitis B-related cirrhosis. J Viral Hepat 20 (Suppl 1): S58-S64, 2013

33. Zhang GL, Zhang T, Ye YN, Liu J, Zhang XH, Xie C, Peng L and Gao ZL: Complement factor 3 could be an independent risk factor for mortality in patients with HBV related Acute-On-Chronic liver failure. BioMed Res Int 2016: 3524842, 2016.

34. Bugdaci MS, Alkim C, Karaca C, Kesici B, Bayraktar B and Sokmen M: Could complement $\mathrm{C} 4$ be an alternative to biopsy for chronic hepatitis B histopathologic findings? J Clin Gastroenterol 45: 449-455, 2011.

35. Lei Z, Mo Z, Zhu J, Pang X, Zheng X, Wu Z, Wang K, Li X, Xie D and Gao Z: Soluble ST2 plasma concentrations predict mortality in HBV-related acute-on-chronic liver failure. Mediators Inflamm 2015: 535938, 2015. 